\title{
EDUCACIÓN
}

\section{Enseñanza del léxico en la praxis educativa paraguaya: reflexiones para su mejora}

\author{
Estela Mary Peralta de Aguayo ${ }^{1}$
}

\section{Resumen}

Introducción: El conocimiento de una lengua entraña conocerla en todos sus niveles. El enfoque de enseñanza de lenguas propuesto por el Ministerio de Educación y Ciencia (MEC) es el comunicativo, mediante el cual se apunta al logro/desarrollo de la competencia comunicativa del estudiante, la cual es la suma de otras competencias como la lingüística, pragmática y sociolingüística. La competencia lingüística envuelve otras competencias, entre ellas a la competencia léxica, que supone el conocimiento del vocabulario de una lengua y la capacidad de emplearlo. El MEC plantea en los programas de estudio para cada ciclo y nivel educativo la comprensión y uso del léxico que se complejiza según la evolución cognitiva de los alumnos. Por tanto, la enseñanza y aprendizaje del léxico es vital, porque por medio de este todo ser humano se apropia del mundo y, en consecuencia, su enseñanza no debe dejarse al azar (Battaner, 1994), lo cual no se ha considerado en los libros de texto o manuales educativos. En el marco del enfoque comunicativo, la enseñanza de la lengua debe partir de un contexto, es decir, una situación extralingüística y un co-texto, esto es, un entorno lingüístico. Los enfoques de enseñanza del léxico también han evolucionado, las tradicionales - que condicen con la teoría estructuralista - y las comunicativas. En cuanto a la tipología de actividades para su enseñanza, Moreno Ramos (2004) resume las convencionales, las lúdicas, las constelaciones y las dramatizaciones. Aprender una palabra no solo se restringe a saber su significado, implica establecer una red a asociaciones en el lexicón mental. Una unidad léxica posee una forma, un significado y un uso. El conocimiento puede ser receptivo y productivo. En los últimos decenios, se ha arraigado el empleo de libros de texto para la enseñanza de lenguas, los cuales deben condensar las propuestas ministeriales y enmarcarse dentro del enfoque metodológico propuesto. En el Paraguay, son exiguos los estudios referidos a la enseñanza de la competencia léxica.

Objetivo: Describir las propuestas de enseñanza del sobre las propuestas de enseñanza del léxico en los libros de texto para la enseñanza del español²,

1. Universidad del Cono Sur de las Américas, Paraguay.

Consejo Nacional de Ciencia y Tecnología, Paraguay.

E-mail: estmary@gmail.com

DOI: $10.26885 /$ rcei.foro.2017.82

2 El estudio se denomina: Los libros de texto y la enseñanza del léxico del español como L1: actividades, concreción del currículum y el uso del diccionario en el aula. Presentado en el 


\section{Enseñanza del léxico en la praxis educativa paraguaya. Peralta de Aguayo}

Comunicación (2015/2016) del segundo ciclo y Lengua y Literatura (2013) del tercer ciclo, de la Educación Escolar Básica

Material y Método: Se ha llevado a cabo un estudio de carácter exploratorio y descriptivo sobre las propuestas de enseñanza del léxico en obras de reciente producción, en los que se ha analizado mediante una guía de análisis: el enfoque metodológico empleado, el enfoque de enseñanza del léxico visualizado, la concreción del currículum, el tipo de unidades léxicas planteadas, las actividades presentadas, las destrezas en que se aborda el componente léxico, los recursos didácticos, los glosarios contenidos en los libros y el planteamiento del uso del diccionario.

Resultados: Los resultados visualizan el planteamiento del enfoque comunicativo, parten de textos reales, otorgando el input suficiente, empero son poco aprovechados para la enseñanza del léxico; el enfoque léxico empleado, no obstante, es estructuralista ya que las actividades propuestas en estos materiales se remiten a las actividades convencionales, profusas en la década del 80, son recurrente los ejercicios de sinonimia/antonimia, campos semánticos e interpretación de frases. Las unidades léxicas presentadas son mayormente, unidades léxicas simple, compuestas, siglas, algunas unidades fraseológicas. Las actividades se agudizan en las destrezas receptivas, esencialmente de compresión escrita, en detrimento de las productivas. Así también, en el proceso didáctico de enseñanza el léxico (Woodward, 2001) se cumplen dos fases, la de exposición a la lengua y percepción de la forma y el significado; mientras que las de almacenamiento mental y uso y mejora no son contempladas. Se percibe la falta de un continuum entre las actividades léxicas y gramaticales, además de la preeminencia de la forma sobre el significado lo cual no condice con los planteamientos de Peñalver (1991), de tomar la semántica como punto de partida y no de llegada. Los glosarios incluidos en los libros evidencian una selección subjetiva e improductiva, limitados a inclusión de voces sin información lexicográfica. De igual manera, el uso del diccionario se remite a la búsqueda puntual de una palabra, con una tendencia mayoritaria a la decodificación. Los hallazgos permiten cuestionar la práctica pedagógica y el desarrollo de la competencia comunicativa de los estudiantes.

Conclusiones: Luego de presentar los resultados de esta investigación previa y examinar las teorías que fundamenten la importancia y necesidad de acrecentar la competencia léxica como vía para el logro de la competencia comunicativa del alumnado se esboza una guía de valoración de los materiales didácticos locales sobre la enseñanza del léxico, considerando el poder hegemónico de los libros de texto en las aulas. Así también, reflexionar la temática en el marco del "Programa de capacitación a los educadores para el mejoramiento de los aprendizajes de niños, niñas, jóvenes y adultos a nivel nacional, del Ministerio de Educación y Ciencia", ya que los docentes son los primeros que deben estar

III Congreso Internacional de RELEX de Lexicografía y Didáctica. Pontevedra, España, 25-27 de octubre de 2017. En esta comunicación, se amplía la primera sección del trabajo con una propuesta de análisis de los libros de textos producidos en el país. 
al tanto de las novedades teóricas existentes sobre la didáctica de las lenguas, igualmente conocer y valorar las ofertas editoriales existentes.

Palabras clave: enseñanza del léxico, competencia léxica, libros de texto.

\section{Referencias}

Battaner, M. P. (1994). La investigación en enseñanza del español/lengua materna: vocabulario y léxico. Actas del Congreso de Lengua Española, 417-429.

Moreno Ramos, J. (2004): Enseñar lengua desde un enfoque léxico. Revista electrónica internacional Glosas didácticas, 11, 162-168. Recuperado de http://www.um.es/glosasdidacticas/numeros/11.html

Peñalver, M. (1991). La Lingüística y la enseñanza de la lengua española en el Bachillerato. Granada: Comares.

Woodward, T. (2001). Planificación de clases y cursos. Madrid: Cambridge University Press. 